\title{
PARTICIPATION IN EUROPEAN WATER POLICY
}

\author{
J.A. van Ast, S.P. Boot \\ Erasmus Centre for Sustainable Development and Management (ESM), \\ Erasmus University Rotterdam \\ P.O. Box 1738, 3000 DR Rotterdam, The Netherlands \\ Tel. +31 10-4082050/Fax +31 104089104 \\ vanast@fsw.eur.nl
}

\begin{abstract}
This paper considers the possibilities for interactive policy-making in European water management. In the new European Water Framework Directive, public information and consultation are major elements in the procedure (process) that leads to River Basin Management Plans. In general, decision making in integrated water management should not be limited to the application of models and desk studies. Important decisions need a high level of participation. In this interactive approach, visions, ideas, patterns of behaviour and solutions to perceived problems of different societal actors can be identified and incorporated into the decision-making process. For example, farmer organisations, environmental groups and associations of house owners, but also individual citizens often have various and differing ideas about measures that change the physical, chemical or biological characteristics of a river basin. Well-organised interaction has two main potential advantages:

1. The quality of the decision will be higher because specific knowledge of people involved and their different views are taken into consideration.

2. The interaction enables exchange of information which can lead to a better understanding of the ins and outs of the specific situation and in this way contribute to public support.

By means of two examples of water related policy issues in Europe, i.e. economic approaches in the Water Framework Directive and Integrated Product Policy, various opportunities for pluralistic as well as corporatist types of participation in modern water management are presented and discussed.
\end{abstract}

Keywords:

Water Policy, Water Management, Stakeholder Participation, Diffuse Sources, Economic Instruments, Product Policy 


\section{Introduction}

In this paper we deal with possibilities for participation of both specific stakeholders and the general public in water management within the Framework Directive on Water Policy (WFD) [EU, 2000]. After a description of the concept of 'participation', we elaborate the concept in relation to interaction based approaches in policy making. The Directive [EU, 2000; preamble, no. 14] literally stresses the importance of such approaches: "The success of this Directive relies on close co-operation and coherent action at Community, Member State and local level, as well as on information, consultation and involvement of the public, including users". Besides general developments in policy making, we discuss specific developments in the domain of water management. We consequently explore whether or not the WFD fits in the trend towards interaction and provides opportunities for the introduction of interaction-based policy approaches in community water policy. In order to build on empirical evidence we selected two cases of interactive policymaking. The first discusses the increasing attention given to economic approaches in water management, the second discusses the newly developing domain of product policy.

\section{Participation in policy making}

Governmental agencies can adopt several roles in the participation process, each with it's own degree of interaction with societal actors. These roles can be seen as steps on a "ladder of participation" (see Figure 1).

Figure 1: Ladder of participation (based on Pröpper \& Steenbeek [1999, p. 51])

\begin{tabular}{|c|c|c|c|}
\hline Step & Style of Governance & Role of Participant & \\
\hline 6 & Facilitative & Initiator & \multirow{4}{*}{ 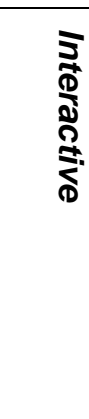 } \\
\hline 5 & Co-operative & $\begin{array}{l}\text { Co-operating } \\
\text { partner }\end{array}$ & \\
\hline 4 & Delegating & $\begin{array}{l}\text { Co-decision } \\
\text { maker }\end{array}$ & \\
\hline 3 & Participating & Advisor & \\
\hline 2 & Consultative & Consultant & \multirow{3}{*}{ 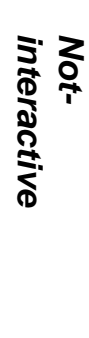 } \\
\hline 1 & $\begin{array}{l}\text { Open } \\
\text { authoritative }\end{array}$ & $\begin{array}{l}\text { "Target group" } \\
\text { of information }\end{array}$ & \\
\hline 0 & $\begin{array}{l}\text { Closed } \\
\text { authoritative }\end{array}$ & None & \\
\hline
\end{tabular}

increasing interaction

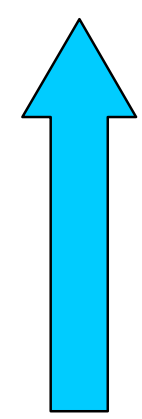


The 'ladder of participation' is an indicator of the government's attitude towards participation. With every step up the ladder, interaction becomes more intense. The second column of figure 1 defines the style of governance and the third column the role of participating actors in the policy-making process.

At the bottom of the ladder there is no participation. Here societal actors do not interact with water managers in the decision-making process. The smallest degree of participation can be found at the first level on the ladder, in which the position of the government can be characterised as open authoritative governance, and the actor is just a target group of research or information. At the second level the government is consultative, and society is principally asked about possible actions to be taken by the government. From the second step down one cannot really speak of interactive policy-making. The third step of the ladder can be called participative governance. Here, society takes on a role as advisor. At the fourth level, the government delegates tasks, and actors become co-decision makers. At the fifth level of the ladder, with a co-operative government, societal actors are partners in policy making. At the highest, sixth degree of interaction the government plays a facilitative role. In this situation, societal actors take the initiative.

In the idealised state of a participative democracy, the aim would be to generate the highest degree of interaction possible. This means that the possibility should be created for societal actors to influence the policy-making process either directly or indirectly. However, this does not necessarily mean that in all cases, actors should be involved at every stage of the policy process.

Generally speaking, two main types of interactive policy-making can be distinguished. The first involves the broad public in the decision making process in a non-organised way. This pluralist type can be considered as the ideal type of interactive policy making in a democratic society, since every citizen has the possibility to exert direct influence on decision making processes. Referenda are an example of this type of interactive policy making. The second type of interactive policy-making involves (organisations of) stakeholders, related to a specific policy-issue in the decision making process. In this way, representatives of specific interests operate more or less in an equal position to governmental authority and to other stakeholders. An example of this corporatist type of policy-making are the negotiations between government, labour unions and employer organisations about collective labour conditions (for an overview of different types of state-society-market interactions, see Ham and Hill [1993]).

In theory, there are two main advantages to (both types of) participation. Firstly, the quality of a decision is potentially higher because the different views and specific knowledge of people involved, can be taken into consideration. Secondly the interaction enables exchange of information, which can lead to a better understanding of the ins and outs of the specific situation and can contribute to public acceptance and support. This situation is the opposite of the practice of many present-day negotiations that now go on behind closed doors, involving selected groups only. Involving too few stakeholders is a threat to democracy, which is especially relevant for the 
corporatist type of policy making. With regard to this type of interaction, it is therefore crucial to be very careful in keeping negotiation process transparent.

From a governmental point of view, a disadvantage of these types of open communication is the possibility that actors striving for other goals than the government get substantially more influence. In this way, a high degree of openness could decrease the extent to which government agencies can attain their goals and can inhibit rapid policy implementation. The first problem calls for an adequate institutional framework for interactive policy making, securing the position of governmental agencies in the negotiations. The second problem calls for careful preparation of the participation process, with at least agreement with the stakeholders about aspects like policy goals and policy means. This can substantially speed up the decision making process and its implementation.

With regard to the corporatist type of interactive policy-making, it is important to make an exhaustive inventory of possible parties to be included in the policy-making process. Therefore, prior to the choice of a "style of governing", an actor-analysis needs to be made. This relates both to the choice of internal actors within the government structure itself and to the choice of external partners. For the realisation of policy goals, the behaviour of stakeholders can be a crucial factor for success. Most of the actors have their own view on solutions for the problems they perceive. For example, farmer organisations, environmental groups, associations of house-owners and individual citizens may all have different ideas about measures that change the physical, chemical or biological characteristics of a river basin. By giving these stakeholders a full position in the decision making process, objections that might arise in the policy implementation phase may be prevented.

\section{New Concepts in Water Management}

As has been pointed out, interaction with the public and with different stakeholders can improve governmental policy and hence the management of water in all its identities. It fits in a global evolution in the water management paradigm, where step by step a development towards "interactive management" of international river basins can be identified [Van Ast, 2001]. Interaction refers here to the society on the one hand, and the water system on the other (see Figure 2). 


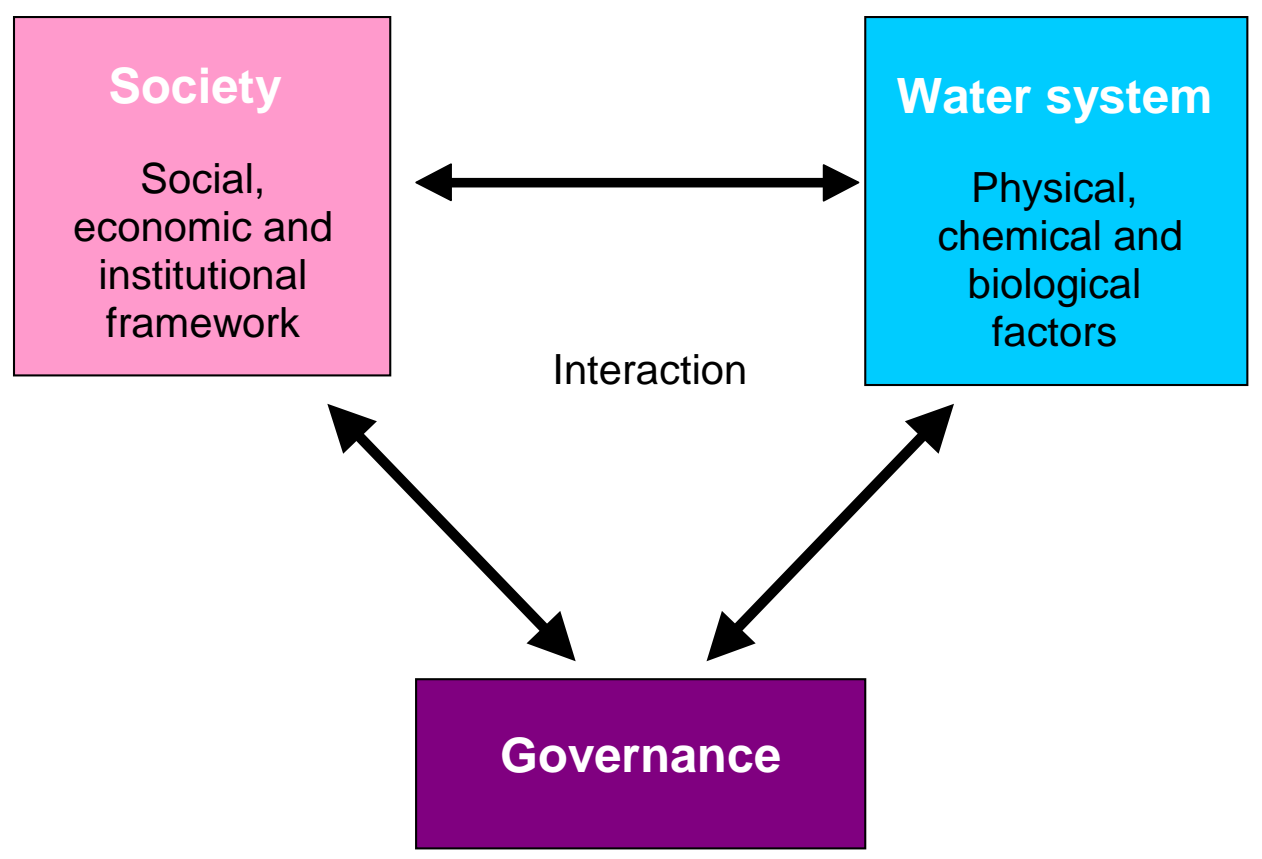

We have already elaborated our view on the kind of interaction between water managers and society. The time that water authorities, just as other governmental institutions could decide about plans, projects and policy aims independently (without involving 'society'), has been left behind. Water managers should at all times monitor relevant processes in society. This makes it possible to adequately react to changes in human behaviour which have impacts on water systems. In addition, monitoring societal processes makes it possible to react to opportunities for the development of new policy approaches.

Besides interacting with society, water managers' relationship with water systems should also be based on interaction. This is why the 'water system' has been included in figure 2 . Interaction with the water systems means that interactive water managers are in a continuous dialogue with the different ecological parameters of the water systems. At every moment they have an overview at their disposal of the state of the river system they manage. This requires intensive monitoring of chemical, physical and biological parameters. In the following sections, two aspects of the WFD are discussed for which interactive policy-making is very relevant.

\section{Interaction in the economic elements of the European Water Framework Directive}

The first example in this article deals with the present interest in economic approaches in the WFD and the opportunities for interactive policy-making with regard to this element. Increasing attention on economic approaches is not just a trend in water management, it is increasingly present in society as a 
whole. This trend can be referred to as the "economisation" of society [Van Ast, 1999].

In the Water Framework Directive, economisation is reflected in, amongst other things:

- $\quad$ "the polluter pays principle" [a.o. preamble no. 11 and no. 38, Article 9];

- the requirement to make an economic analysis of (present and future) water use in every river basin district [a.o. Article 5 and Annex III];

- the economic assessment of potential measures (f.e. through cost effectiveness analysis) [a.o. Annex III];

- developments towards water pricing [a.o. Article 5 and Annex III]; which may be see as an element of

- the requirement of full recovery of cost of water services [Article 9];

- optional supplementary measures to be taken by Member States, such as economic or fiscal instruments [Annex VI];

- determining penalties applicable to breaches of the national provisions adopted persuant to this Directive that are effective, proportionate and dissuasive [Article 23].

Furthermore, it is explicitly recognized that the protection of the water status within river basins, will provide economic benefits [preamble no. 17].

With regard to water policy-making (both formulation and implementation) in general, five main steps can be distinguished. Figure 3 indicates the role of economic analysis in each of these stages.

Figure 3: Economic aspects of policy-making for water management

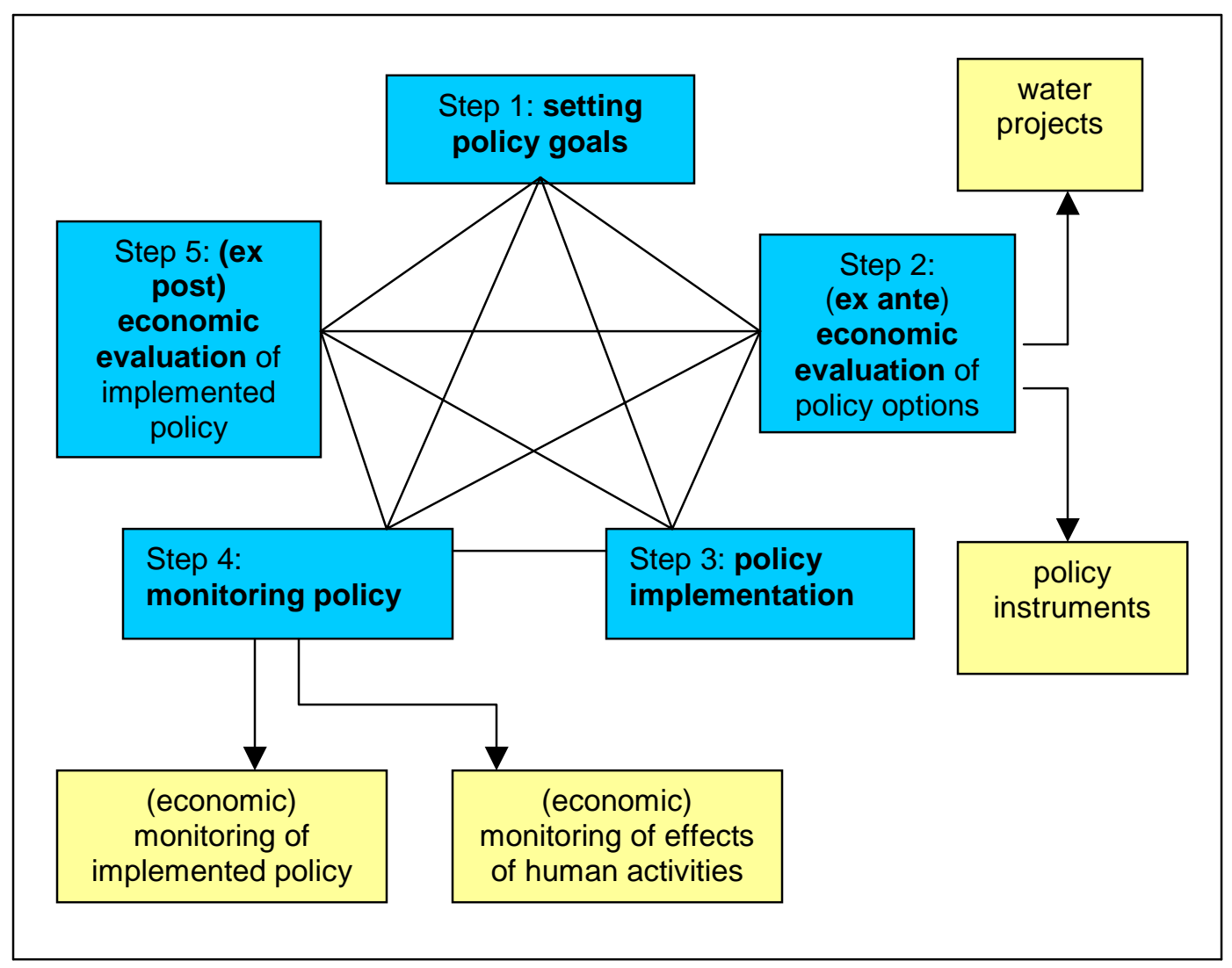


The role of economics in the implementation of the WFD is discussed for each of the steps from the figure. The first phase of the implementation of the WFD, the making of River Basin Management Plans, includes an economic analysis of the major economic activities in each river basin, that affect the state of the water in the basin, either in a quantitative or a qualitative way. This stage corresponds with step 4 in the figure. Based on the results of this economic analysis, gaps between the goals set (step 1) in the WFD and the current state of the river basin can be assessed. The policy goals refer to desired states of the water bodies in the future. Whether or not there is an explicit role for economic analysis depends on the nature of the policy approach. In some (urgent) situations, a goal is set that has to be reached regardless of the costs. In most situations, however, the goals depend among other things on the costs of the measures to reach them (see for example Art. 4 of the WFD). After assessing the gap, water managers can formulate ways to close this gap (different policy options). Ex ante economic evaluation of these policy options (step 2) can help in assessing the (expected) most cost effective (set of) policy measures. This means that an economic analysis is made of the expected costs associated with different policy options for reaching a certain policy goal. During the implementation (step 3) and effectuation of these measures, economic monitoring of the policy measures (step 4) is needed to prepare an ex post economic evaluation of the implemented policy (step 5). The fourth step includes (economic) monitoring of the effects of past and present human activities (including the implemented policy) on the state of the water bodies. Based on the ex post economic evaluation, the (set of) policy measures can either be corrected or continued.

It should be noted that the policy-making process described is not a linear but an iterative process and that the order presented in the figure is not fixed. Within the process, several shortcuts and small loops may exist between all of the steps. This is indicated by the web-like structure between the different steps. Besides, the figure presented is a rather limited and formal representation of a part of the policy-making process, that in reality will likely be preceded by less formal and less structured stages that involve societal and then political agenda setting. These phases (and possibly many other) are not represented in the figure.

As was mentioned earlier, increasing attention for economic approaches in water management is one of the main elements of the European Water Framework Directive. The question here is what role public and stakeholder participation can play with regard to these economic approaches. As was mentioned earlier, public and stakeholder participation is most explicitly dealt with in Article 14 of the directive. This article states that "Member States shall encourage the active involvement of all interested parties in the implementation of this Directive, in particular in the production, review and updating of the river basin management plans". This logically also relates to the economic aspects of the implementation of the Directive.

A first step towards implementing the WFD is the establishment of river basin management plans (RBMPs). These plans are meant as a 'plan of operation', 
indicating for each river basin in what way the overall goals of the WFD will be reached. RBMPs therefore are not a goal in themselves, but an instrument to reach the overall goals of the framework directive. Since RBMP's are a translation of the WFD for each specific river basin, RBMP's provide tailormade solutions. Inhabitants of each river basin can provide water managers with useful information about many aspects of the river basin. It is important therefore, that inhabitants are involved in all stages of the process of making, implementing, monitoring and evaluating the RBMP's, covering all stages mentioned in Figure 2. Citizens and stakeholders have a role to play in each of these steps by providing water managers with relevant information and by participating in this process as partners to water managers, probably leading to an increase in public support.

It can be argued however, that although the WFD provides for opportunities for participation or interactive policy making, citizens and stakeholders were not actively involved in the setting of the boundary conditions for economic analysis. Generally speaking, it is rather complicated to involve the public and other stakeholders in the methodical details of economic evaluations in water management. However, we think there are realistic opportunities to involve the interested parties in, a.o.:

a. defining the scale at which the various components of economic analysis (for example with regard to the RBMPs) have to be performed [Garin \& Rinaudo, 2002]. Although this has already been done for the WFD (Preamble 38, Article 5 and Annex III of the WFD state that the river basin district is the appropriate and obligatory scale), a specific local situation may call for an exception to the guideline. Citizens and stakeholders may help in assessing whether the scale stipulated in the guideline is the appropriate scale for economic analysis in their specific river basin. It must be noted here that the importance of choosing the right scale of analysis and the involvement of public and stakeholders in this respect is stressed in the guidance document on economics and the environment (WATECO, 2002, pp. 38 - 45).

b. determining the weight that is given to economic evaluations in relation to other types of evaluations;

c. determining the conditions for economic evaluations (f.e. with regard to issues of time and spatial scale and the height of crucial parameters);

d. setting the goals of the River Basin Management Plans;

e. designing and implementing economic policy instruments (by hearing their demands and ideas); and

f. the evaluation and revision of economic policy.

Involving interested parties in setting the conditions for (economic) policymaking can help raise understanding of the motives behind policy measures as advocated by the WFD and consequently increase public support or make opposition explicit. Besides, the input from experts and stakeholders can help in finding management options previously not considered as well as data relevant for economic analysis.

Notwithstanding the above, the question still remains how the interested parties can actually be involved in the decision making process. Within the 
corporatist type of interaction this can be implemented by representation of groups of stakeholders, like customers. For example, the setting up of independent customer councils with regard to the privatisation of the water industry in England and Wales [Reiter, 1999] has shown that customer representation can be an effective mechanism to make the voice of the public heard in policy-making. This example relates mainly to the points $e$. and $\mathrm{f}$. in the list above.

Within the pluralist type of interaction the opinion of unorganized parties could be discovered by means of interviews, polls or, in crucial policy issues, by giving people a vote in a referendum. An example of interaction with unorganized experts and stakeholders is the performance of semi-structured interviews with experts and the main local actors in the water management field in two sub-basins in the south of France as described by Garin \& Rinaudo [2002]. The goal of these interviews was to make an inventory of stakeholders' and experts' knowledge with regard to the design and implementation of RBMP's. Garin and Rinaudo argue that a confrontation of stakeholders and the experts' knowledge is required to bridge potential gaps between experts and public visions of the economic issues at stake (in this case 'cost recovery analysis' and 'cost-effectiveness analysis'). According to the authors, this confrontation should take place before the economic analysis gets started in order to facilitate the emergence of a shared understanding of the issues that need to be addressed and the methodological tools that should then be used by economists. This is likely to reduce the risk that the results of the economic analysis are contested or even rejected during the general public consultation process that takes place after the analysis is complete.

Garin and Rinaudo [2002] used detailed semi-structured individual interviews as a method to identify viewpoints of the main local stakeholders on (i) the hydrological dysfunction of rivers, (ii) issues and conflicts related to water, (iii) alternative management options and (iv) the scale at which public participation could take place. Actors mentioned were farmers, hydropower companies, the tourism sector, wastewater treatment utilities and drinking water companies. The authors identified groups of water bodies with similar socio-economic and hydrological characteristics in the sub-basins as homogeneous areas. They conclude that early consultation of stakeholders in the homogeneous areas studied, could prevent conflicts, help reveal the hydrological and economic relationships and identify the scale at which the major economic issues should be addressed.

Large infra-structural projects in The Netherlands have shown that the decision making process can be hindered substantially if stakeholders are heard only in a late stage of the decision making process when decisions have in fact already been taken. Involvement of stakeholders therefore should take place as early as possible. It is important to add that as a condition for public support for government policy, government organisations themselves cannot be excluded from the chosen policy. To put it clearly, these organisations should serve as an example of "Practicing what you Preach". 
According to Garin and Rinaudo [2002] their case shows that the estimation of costs associated with alternative programmes of measures could benefit from stakeholder input. They argue that the knowledge of stakeholders helps especially in identifying indirect costs of different programmes of measures. The same point applies to the reporting on cost recovery. Stakeholders can help to identify beneficiaries of certain water services, including stakeholders benefiting from external effects. Garin and Rinaudo mention the unreliability of the information from private actors as one of the main risks likely to be encountered in performing economic analysis in the way presented above. There is a risk of manipulation of the analyst by stakeholders due to asymmetry of information as well as information costs.

Nevertheless, as a total, the arguments in favour of this type of interaction, can be considered stronger than the arguments against, specifically when its time gain as a result of reduced risk of rejection by the public is taken into consideration

\section{Interaction regarding Integrated Product Policy (IPP)}

A second example of interactive policy making are the measures against diffuse pollution. When looking closely at current pollution problems in the different river catchments, it is clear that diffuse sources are one of the main threats to water quality. Examples are nutrients, pesticides, heavy metals and organic material. Recently, awareness of hazardous substances has increased, like the many additives to synthetics (softeners, pesticides, fragrances) causing problems when they leach into the air, into the soil and in many cases eventually into the water. Other examples are heavy metals (copper cables or zinc roof material) and medicines (like oestrogens). Various substances can work like artificial hormones. Specifically the combined effects of all of these substances could have surprisingly severe impact on organisms.

Under current circumstances, a complete ban on most of the products causing diffuse water pollution is not realistic. In some cases the individual contribution per product to the total load of contamination can be too low for a full ban. In other cases the effects can be unclear or the products can be too important for society. In addition, free market regulation, not in the last place from the EU, can be too high a barrier.

As far as environmental measures against diffuse sources are concerned, the WFD states in article 10 that "Member States shall ensure the establishment and/or implementation of: (a) the emission controls based on best available techniques, or (b) the relevant emission limit values, or (c) in the case of diffuse impacts the controls including, (...) best environmental practices". With respect to technical measures, the directive follows the practices brought forward in the Council Directive concerning Integrated Pollution Prevention and Control, or IPPC [EU, 1996]. 
In the formulation and implementation of these types of measures, the Commission takes into account recommendations from all relevant stakeholders. For example, representatives of European business organisations, European environmental organisations, and others are invited to collaborate in searching for good practice in water pollution policy. For both point and diffuse sources the main objective is the identification of the most appropriate, cost-effective product and process control.

However, how is it possible to find the Best Environmental Practices regarding products? One of the interaction based options available is the implementation of Product Oriented Environmental Management [De Bakker \& De Gaspard, 2001], or in short: "(Integrated) Product Policy". This is defined as "the policy that intends to reduce the environmental damage of products by influencing the economic actors that deal with them" [Oosterhuis et. al. 1996]. To this definition, we may add "in all stages of the product chain": especially for the reduction of pollution from diffuse sources, product oriented policy strategies have potential benefits over more traditional "command and control" based regulation. For that reason, the European Union [EU, 2001] embraces this approach as one of the spearheads of environmental policy directed to industry in its Green Paper of February 2001 "Integrated Product Policy" (IPP).

The aims of IPP are the stimulation of green products, enhancement of sustainable production and the institutionalisation of a European Eco-label. Already during the formulation of the IPP programme, the European Commission facilitated a number of workshops on particular aspects of Product Policy. Here experts and representatives of stakeholders were consulted jointly about the implementation of Product Policy. One of the topics was Environmental Product Declarations, which are documents of the environmental characteristics of products, based on an integrated chain analysis. Another topic was the development of guidelines for Life Cycle Analysis and for Ecodesign. Furthermore, the introduction of Product Panels was discussed. These are groups of stakeholder representatives, working together on reducing environmental problems arising from a specific group of products.

The basic idea behind the Green Paper on Integrated Product Policy is that industry is ready to take its own responsibility in solving pollution problems resulting from their activities, including products. The trend of going from the vertical "command and control"-paradigm that allows government agencies to determine from a hierarchical position what citizens should do, towards more horizontal relations between government and society is obvious. In presentday society, societal actors have a more equal position in governmental decision-making processes.

Integrated Product Policy implies the concept of the "product life cycle" [EU, 2002] (see figure 3). This cycle covers all the areas of a product's life; from the extraction of natural resources, the production of raw material, through their design, assembly, marketing, distribution, sale and use to their eventual disposal as waste or reuse. For the operationalisation of integrated chain 
management, instruments are developed for calculating environmental impact, like Life Cycle Analyses (LCA's) [Frankl \& Rubik, 2000]. In every stage of the product life cycle, specific actors play a role, varying from the mining sector to the waste processing industry and all actors in between, like designers, marketing people and retailers.

Figure 3: the Product Life Cycle

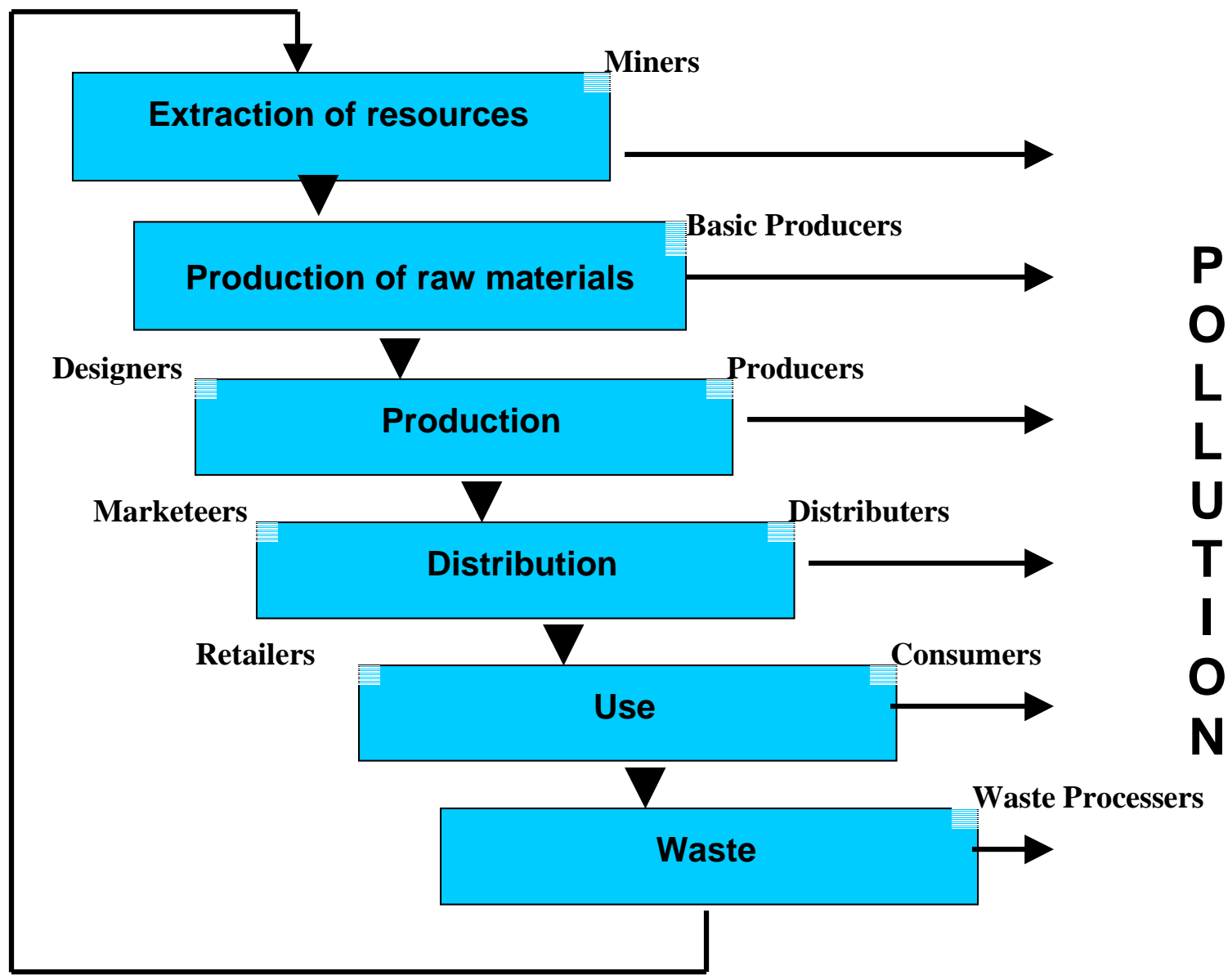

Integrated Chain Management, the management of wastes and material flows from all product phases in an integrated way, attempts to stimulate the actors involved in each of the individual phases to decrease the negative influence on the environment. Historically, the focus on point sources has directed emission policy to the phases of "production" and of "waste". More recently, with the introduction of prevention measures, the phases of "resource extraction" and "product design" were included. The "user" phase, which in general causes substantial - diffuse - pollution, has not received much attention so far, and certainly not from water managers. However, an integrated product cycle approach can provide valuable insights for water managers, especially in relation to diffuse sources of pollution [Van Ast et. al., 2002]. Industry included Product Policy into "Product Stewardship", a concept that fits perfectly well to the rapidly expanding "Responsible Care" business ethics. Initiated by the chemical industry, it is based on the implication of social and environmental responsibility for all activities as an integrated 
element of general management (paying attention to "People, Planet and Profit"). The consequence is that producers (should) deal with the environmental impact of their products in the whole chain of the product cycle, or so to say, from the cradle to the grave.

\section{Concluding Remarks}

It will be clear by now that the WFD provides many opportunities for interactive water management. It is suggested that decision making in modern water management will be based more and more on participation of various societal actors. At the same time water managers will also have to interact in an intensive way with the increasingly complex set of natural factors associated with the water system.

When looking at various economic approaches of the WFD, it appears that increasingly both the pluralistic and the corporatist type of participation are used in the implementation process. The WFD provides for several opportunities for participation, which will be elaborated in the guidance document on public participation. It can be argued however, that citizens and stakeholders could also play an interesting role in defining the conditions under which the economic principles, tools and instruments have to be implemented. Although the public cannot anymore be included in setting the terms for the WFD, interaction in this sense is still possible, for example by applying the guidelines of the economic requirements of the WFD not too rigidly. In this way, there will be some room left for adjusting the rules if needed, based on specific regional circumstances in river basins districts and the demands and desires of the local public. Only if the public is involved in defining the conditions for economic analysis, there will be enough participation to speak of interactive policy making (see figure 1).

As far as Product Policy is concerned, the facilitative role of government for interaction in society is clear. When industry keeps its word and takes responsible care seriously, representatives of companies will increasingly think, in interaction with the water managers, about possible solutions for potentially polluting products. This corporatist variant of interactive policy making means that water managers will more and more invite representatives of companies that (plan to) produce products with (potentially) undesired effects on the water quality, for discussions about ways to deal with emerging problems. At the highest step of the participation ladder, water authorities could facilitate the development of optimal solutions for the problems caused by diffuse sources.

However, the success of the interactive methods presented in this article depends on fulfilling some basic conditions. One of the crucial factors is the ability of water managers to construct the appropriate organisational setting to make these methods effective. Powerful water authorities of complete and when necessary international - catchment areas will be more influential than small local organisations. Although local authorities still have an important role to play, the need for powerful governmental organisations strengthens the plea for supra-national commissions for main issues in water management on 
the level of river catchments. This topic should be explored further in the future.

\section{References}

Ast, J.A. van, 2001. Interactief waterbeheer in grensoverschrijdende riviersystemen. In: Milieu, tijdschrift voor Milieukunde, Vol. 16, No. 1, 11-22.

Ast, J.A. van, 1999. Trends Towards Interactive Watermanagement; Developments in International River Basin Management, In: Physics and Chemistry of the Earth (B), Vol. 24, No 6, 597-602.

Ast, Jacko van, Kees Le Blansch, Frank Boons en Stephan Slingerland, 2002. Potenties van productbeleid voor waterkwaliteitsbeheer, onderzoek van $Q A+$ en ESM in opdracht van het Ministerie van Verkeer en Waterstaat / RIZA, Den Haag.

Bakker, Frank De and Anna de Gaspard, 2001. Product-oriented environmental management: a study of capability-building, stakeholder orientation and continuous improvement regarding products' environmental characteristics in firms, Twente University Press, Enschede.

EU, 1996. (European Union), Council Directive concerning integrated pollution prevention and control, 1996/61/EC of 24 September 1996, L 257, 10/10/1996 p. 0026.

EU, 2000. (European Union), The Water Frame Work Directive, (establishing a framework for Community action in the field of water policy), 2000/60/EC of 23 October 2000, L $327,22 / 12 / 2000$ P. 0001.

EU, 2001. (European Union), Integrated Product Policy, Green Paper on Integrated Product Policy, Commission of the European Communities, COM 2001, 68 final, Brussels.

EU, 2002. (European Union), Integrated Product Policy, Website European Commission, http://www.europa.eu.int/comm/environment/ipp/integratedpp.htm

Frankl, Paolo, Frieder Rubik, 2000. Life cycle assessment in industry and business: Adoption patterns, applications and implications. Springer -Verlag, Berlin Heidelberg.

Garin, P., J.-D. Rinaudo, 2002. Building on stakeholder knowledge and information for developing the economic analysis, Conference proceedings, Day 1, of "Europe of Water, Water of the Europeans", organized by the EU, 18 \& 19 March 2002, Lille, France

Ham, C. and M. Hill, 1993. The Policy Process in the Modern Capitalist State, Harvester Wheatsheaf, London.

Oosterhuis, Frans, Frieder Rubik, Gerd Scholl, 1996. Product policy in Europe: New environmental perspectives, Prepared within the project "Product policy in support of environmental policy", Kluwer academic publishers, Dordrecht.

Pröpper, I.M.A.M., Steenbeek, D.A., 1999. De aanpak van interactief beleid: elke situatie is anders ("The approach of interactive policy making: each situation is different"), Coutinho, Bussum

Reiter, S., 1999. Implementing water pricing policies; Transparency and customers' participation in water pricing policies, Pricing water; Economics, Environment and Society; Conference Proceedings Sintra, 6 and 7 September 1999, pp. 241 - 246.

WATECO, 2002. Working Group on Economics and the environment, the implementation challenge of the water framework directive, a guidance document, http://forum.europa.eu.int/Public/irc/env/wfd/library?l=/framework_directive/guidance_do cuments/economic_wateco\&vm=detailed\&sb=Title 